\title{
Efficacy and safety of different doses of evolocumab in reducing low-density lipoprotein cholesterol levels: A meta-analysis
}

\author{
CHENG CHENG, SIJIA SUN, YAFENG ZHOU and XIANGJUN YANG \\ Department of Cardiology, The First Affiliated Hospital of Soochow University, Suzhou, Jiangsu 215006, P.R. China
}

Received November 20, 2015; Accepted September 13, 2016

DOI: $10.3892 /$ br.2016.766

\begin{abstract}
Evolocumab has been considered as an efficacious, safe and promising therapeutic modality for hypercholesterolemia and is associated with cardiovascular diseases. The efficacy and safety of two different doses of evolocumab were evaluated and the safety of evolocumab was compared with that of a placebo and ezetimibe. PubMed and EMBASE databases were searched and randomized controlled trials that examined the effect and safety of evolomucab compared with a placebo and ezetimibe were retrieved. Two authors independently performed article reviews and study quality evaluations. Odds ratios (ORs) were calculated using a fixed or random-effects model [95\% confidence intervals (CIs)]. In the direct comparison, a significant reduction was observed in the muscle-associated events compared with ezetimibe $[\mathrm{OR}=0.54$ (95\% CI, 0.31-0.93); $P(Z)=0.03, P(Q)=0.43, I^{2}=0 \%$ ]. In the adjusted indirect comparison of evolocumab $140 \mathrm{mg}$ Q2W vs. evolocumab $420 \mathrm{mg}$ Q4W, no significant differences in efficacy $[\mathrm{OR}=1.04(95 \% \mathrm{CI}, 0.55-1.99) ; P(Z)=0.90]$ or adverse events $[\mathrm{OR}=1.08$ (95\% CI, 0.66-1.74); $P(Z)=0.76]$ were identified. The funnel plots of these direct comparison studies indicated that there was no publication bias. The results of this meta-analysis demonstrate that evolocumab significantly reduced low-density lipoprotein cholesterol levels, and no difference was noted between evolocumab $140 \mathrm{mg} \mathrm{Q} 2 \mathrm{~W}$ and evolocumab $420 \mathrm{mg}$ Q4W. Furthermore, evolocumab had fewer muscle-associated events than ezetimibe.
\end{abstract}

\section{Introduction}

Reduction in low-density lipoprotein cholesterol (LDL-C) levels has been included in practice guidelines as a fundamental method of reducing cardiovascular events and mortality. Based on previous studies, statin therapy has been considered

Correspondence to: Professor Xiangjun Yang, Department of Cardiology, The First Affiliated Hospital of Soochow University, 188 Shizi Road, Suzhou, Jiangsu 215006, P.R. China

E-mail: xiangjunyangdoc@163.com

Key words: evolocumab, efficacy, safety, meta-analysis as a first-line treatment strategy for targeting atherosclerotic cardiovascular disease (1-4). While receiving moderate- or high-intensity statin therapy, numerous patients were unable to achieve LDL-C concentrations $<70 \mathrm{mg} / \mathrm{dl}$. In addition, certain patients terminated statin therapy due to their inability to tolerate the effective doses and experiencing adverse events. Therefore, non-statin therapy for LDL-C reduction has been considered, and novel effective medication and treatment strategies for reducing LDL-C levels have become a focus of research.

During the past 3 years, monoclonal antibodies, which inhibit proprotein convertase subtilism/kexin type 9 (PCSK9), have emerged as a novel class of therapeutic agent that target LDL-C levels (5). Evolocumab, a fully human monoclonal antibody, effectively reduced LDL-C levels and has been investigated in phase 3 trials (6-10). In these trials, the patients were randomized to groups of placebo, ezetimibe, $140 \mathrm{mg} \mathrm{Q} 2 \mathrm{~W}$ or $420 \mathrm{mg}$ Q4W evolocumab. When compared with the control group, the two different doses of evolocumab significantly reduced the LDL-C levels. However, to the best of our knowledge, there are no studies that demonstrate different outcomes between the two different doses of evolocumab. In the current adjusted indirect meta-analysis, the efficacy and safety of two different doses of evolocumab were evaluated.

\section{Materials and methods}

Literature search strategy. PubMed (https://www.ncbi.nlm. nih.gov/pubmed) and Embase (https://www.embase.com) were searched from January 2000 to April 2015, utilizing the following search terms without language restrictions: (Randomized trial OR clinical trial) AND blind OR random AND control (placebos OR ezetimibe) NOT (comment OR editorial OR meta-analysis OR letter) AND (proprotein convertase subtilisin/kexin type 9 OR PCSK9) inhibitor (evolocumab OR AMG145) AND (140 mg Q2W OR 420 mg Q4W) AND efficacy (LDL-C level OR LDL-C concentration) OR safety OR tolerability. Two reviewers (C.C. and S.S.) evaluated the identified titles, and the manuscripts were retrieved when the reviewers deemed them to be potentially relevant. The results were evaluated to determine whether data on PCSK9 inhibitors had been reported.

Study selection. The review included high quality studies fulfilling the following inclusion criteria: i) Randomized, 


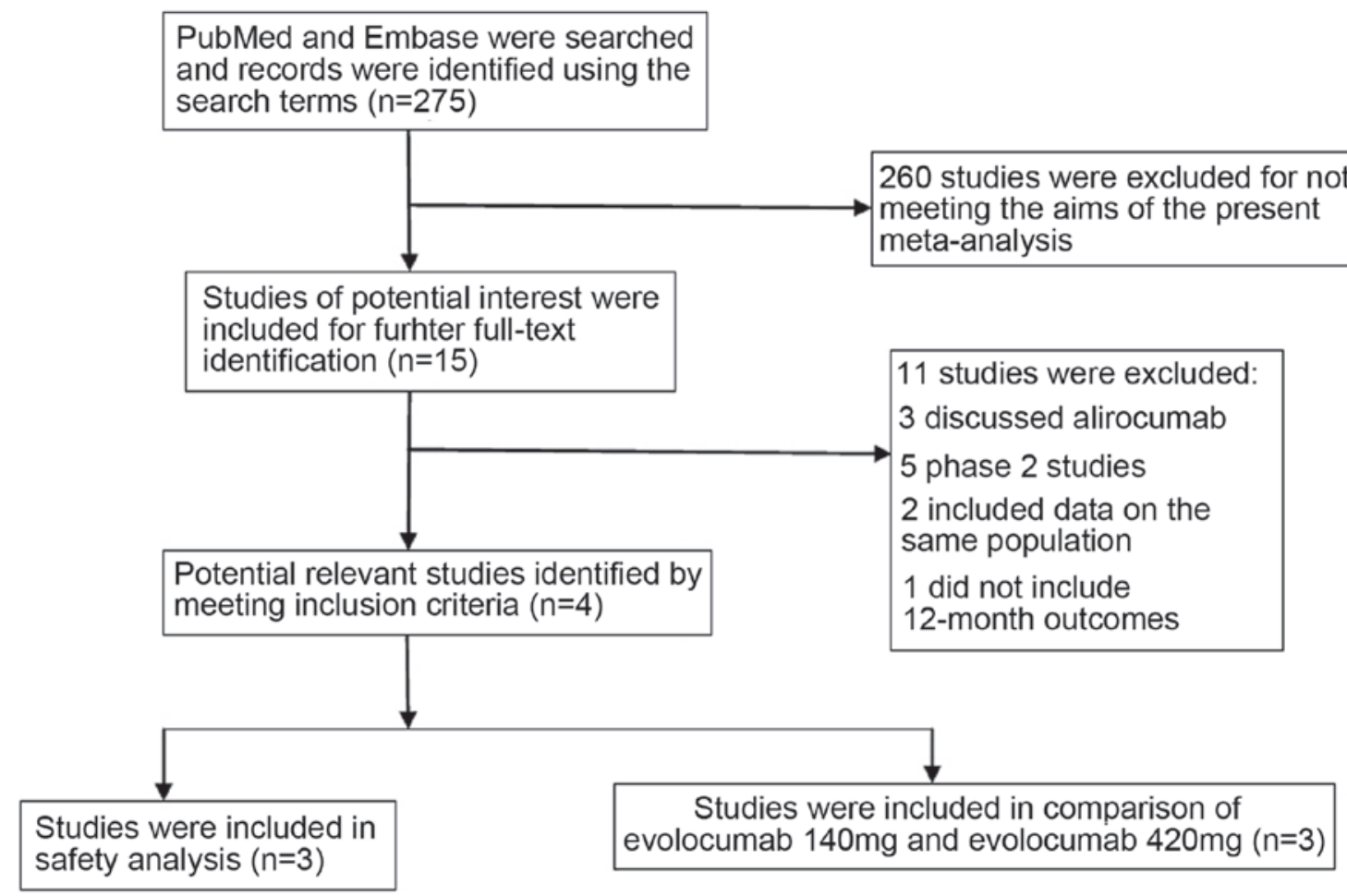

Figure 1. Study flow chart.

controlled phase 3 trial comparing evolocumab, placebo or ezetimibe, with a follow-up of 12 months; ii) the report supplied data on the rate of patients who achieved LDL-C concentrations $<70 \mathrm{mg} / \mathrm{dl}$ or data on the percentage of adverse events; iii) analysis was performed on evolocumab $140 \mathrm{mg}$ Q2W and $420 \mathrm{mg}$ Q4W; iv) when different studies reported on the same population, the study that included a larger sample size and performed evaluation using more comprehensive methods was included.

Data extraction. The following data elements were extracted from each report according to a fixed protocol: Author, publication year, study design, characteristics of trial participants, median follow-up, mean age, and ratio of males, females, diabetes cases, smokers and hypertension cases, as well as data regarding efficacy and safety separated by the different doses of evolocumab. For studies with more than one control group, the most appropriate control group was used. Two authors (C.C. and S.S.) independently conducted the data extraction, and any disagreement was resolved by discussion.

End-points and definitions. The efficacy end-point was the percentage of patients who achieved LDL-C concentrations $<70 \mathrm{mg} / \mathrm{dl}(1.8 \mathrm{mmol} / \mathrm{l})$. The primary safety end-point was the rate of any adverse events. The secondary safety end-point included back pain, headache, nasopharyngitis, muscle-associated events and potential injection-site reactions. All missing data from studies were obtained from supplements.

Statistical analysis. Random-effect odds ratios (ORs) and 95\% confidence intervals (CIs) were calculated using Review
Manager 5.3 (Copenhagen: The Nordic Cochrane Centre, The Cochrane Collaboration, Denmark), and the outcomes that demonstrated a smaller heterogeneity $\left(I^{2}<50 \%, \chi^{2}\right.$ test; two-tailed $\mathrm{P}<0.1)$ were confirmed by a fixed-effects model to avoid small studies being overly weighted. Two-tailed $\mathrm{P}<0.05$ was considered to indicate a statistically significant difference $(11,12)$. Secondly an Indirect Meta-analysis Tool (Metcardio; Turin, Italy) was used for the adjusted indirect comparison according to Song et al (13). Pooled OR (comparing evolocumab $140 \mathrm{mg}$ Q2W or evolocumab $420 \mathrm{mg}$ Q4W vs. placebo) and interaction OR for evolocumab $140 \mathrm{mg}$ Q2W or evolocumab $420 \mathrm{mg}$ Q4W was calculated. In addition, pertinent $95 \% \mathrm{CI}$ and $\mathrm{Z}$ scores for two-tailed hypothesis testing were calculated $(\mathrm{P}<0.05$ was considered to indicate a statistically significant difference). The interaction $\mathrm{OR}_{\text {evolocumab }} 140 \mathrm{mg}$ Q2W vs. evolocumab $420 \mathrm{mg}$ Q4W Was calculated as follows: In $\left(\mathrm{OR}_{\text {evolocumab } 140 \mathrm{mg} \text { Q2W vs. evolocumab } 420 \mathrm{mg} \mathrm{Q} 4 \mathrm{~W}}\right)=\ln$ $\left(\mathrm{OR}_{\text {evolocumab } 140 \mathrm{mg} \text { Q2W vs. placebo }}\right)$ - In ( $\left.\mathrm{OR}_{\text {evolocumab } 420 \mathrm{mg} \text { Q4W vs. placebo }}\right)$,

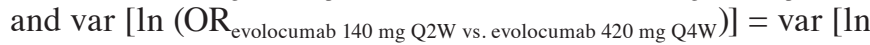
$\left.\left(\mathrm{OR}_{\text {evolocumab } 140 \mathrm{mg} \text { Q2W vs. placebo }}\right)\right]+\operatorname{var}\left[\ln \left(\mathrm{OR}_{\text {evolocumab } 420 \mathrm{mg} \text { Q4W }}\right.\right.$ vs. placebo)], where $\ln$ is the natural logarithm, and var is the variance.

For the direct meta-analysis, a funnel plot was generated for assessment of publication bias; in addition, sensitivity analysis was conducted by removing the study one by one when a significant heterogeneity was observed.

\section{Results}

Study selection and characteristics. The initial search identified 275 reports from PubMed and Embase. After screening 
Table I. Characteristics of included studies.

\begin{tabular}{lcccc}
\hline & \multicolumn{3}{c}{ Study } \\
\cline { 2 - 5 } Characteristic & LAPLACE-2 & MENDEL-2 & GAUSS-2 & RUTHERFORD-2 \\
\hline First autor (Ref.) & Robinson et al (7) & Koren et al (8) & Stroes et al (9) & Raal et al (10) \\
Year & 2014 & 2014 & 2014 & 2015 \\
Patients (n) & 1,896 & 614 & 307 & 329 \\
Median follow-up (weeks) & 12 & 12 & 12 & 12 \\
Age (years) & 59.8 & 53.2 & 61.7 & 51.2 \\
Males (\%) & 54.2 & 31.1 & 54.1 & 42.2 \\
Diabetes (\%) & 15.5 & 0.2 & 20.2 & NA \\
Smoker (\%) & NA & 11.7 & 7.8 & NA \\
Hypertension (\%) & NA & 28.7 & 58.9 & NA \\
\hline
\end{tabular}

the titles and abstracts, 15 articles (6-10,14-23) were selected and underwent further full-text identification. Subsequently five studies $(14,20-23)$, which were phase 2 studies, were excluded; three studies (15-17) were regarding alirocumab, two $(18,19)$ included data on the same population, and one study (6) did not include 12-month outcomes (Fig. 1). Four publications (7-10) were included in the current meta-analysis. Three studies $(7,8,10)$ were included in the indirect comparison of evolocumab $140 \mathrm{mg}$ Q2W and evolocumab $420 \mathrm{mg}$ Q4W without the Goal Achievement after Utilizing an Anti-PCSK9 Antibody in Statin Intolerant Subjects (GAUSS-2 trial) (9), which did not include a placebo group. In the safety analysis, the RUTHERFORD-2 Investigators (10) were excluded, as it does not contain precise data on placebo and ezetimibe groups. The details are presented in Tables I and II.

Statistical analysis. In the direct comparison, the meta-analytic pooling implied that evolocumab markedly reduced the LDL-C level to $<70 \mathrm{mg} / \mathrm{dl}(1.8 \mathrm{mmol} / \mathrm{l})$ when compared with the placebo $[\mathrm{OR}=70.86,95 \% \mathrm{CI}, 51.28-97.91$; $P(Z)<0.01, P(Q)=0.82, I^{2}=0 \%$ ] (Fig. 2), without significant differences noted in adverse events $[\mathrm{OR}=1.09,95 \% \mathrm{CI}$, 0.86-1.39; $P(Z)=0.47, P(Q)=0.65, I^{2}=0 \%$ ] (Fig. 3), back pain $[\mathrm{OR}=0.92,95 \% \mathrm{CI}, 0.49-1.72 ; P(Z)=0.79, P(Q)=0.18$, $\left.I^{2}=38 \%\right]$, headache [OR=0.84, 95\% CI, 0.50-1.42; $P(Z)=0.52$, $\left.P(Q)=0.69, I^{2}=0 \%\right]$, nasopharyngitis $[\mathrm{OR}=1.60,95 \% \mathrm{CI}$, 0.71-3.60; $P(Z)=0.26, P(Q)=0.85, I^{2}=0 \%$ ], muscle-associated event $[\mathrm{OR}=1.24,95 \% \mathrm{CI}, 0.52-2.93 ; P(Z)=0.63, P(Q)=0.26$, $\left.I^{2}=25 \%\right]$ and potential injection-site reactions $[\mathrm{OR}=1.22$, 95\% CI, 0.61-2.43; $\left.P(Z)=0.57, P(Q)=0.30, I^{2}=19 \%\right]$. All the data on comparison of evolocumab $140 \mathrm{mg}$ Q2W vs. placebo or evolocumab $420 \mathrm{mg}$ Q4W vs. placebo are presented in Table III. A head-to-head comparison of evolocumab $140 \mathrm{mg}$ Q2W vs. evolocumab $420 \mathrm{mg}$ Q4W demonstrated no significant differences in the efficacy $[\mathrm{OR}=1.04,95 \% \mathrm{CI}$, $0.55-1.99 ; P(Z)=0.90]$ and the risk of back pain $[\mathrm{OR}=1.48$, 95\% CI, 0.15-14.53; $P(Z)=0.73]$, headache $[\mathrm{OR}=0.68,95 \% \mathrm{CI}$, $0.23-2.06 ; P(Z)=0.50]$, nasopharyngitis $[\mathrm{OR}=1.28,95 \% \mathrm{CI}$, 0.24-6.82; $P(Z)=0.77]$, muscle-associated events [OR=4.43, 95\% CI, 0.32-59.31; $P(Z)=0.27]$, potential injection-site reactions $[\mathrm{OR}=2.09,95 \% \mathrm{CI}, 0.34-12.71 ; P(Z)=0.42]$ and any adverse events $[\mathrm{OR}=1.08,95 \% \mathrm{CI}, 0.66-1.74 ; P(Z)=0.76]$ (Table IV).

In the overall safety analysis, a significant reduction was observed in the muscle-associated events compared with ezetimibe $[\mathrm{OR}=0.54,95 \% \mathrm{CI}, 0.31-0.93 ; P(Z)=0.03$; $\left.P(Q)=0.43, I^{2}=0 \%\right]$. No obvious difference in the risk of headache $[\mathrm{OR}=0.77,95 \% \mathrm{CI}, 0.48-1.24 ; P(Z)=0.27$, $\left.P(Q)=0.72, I^{2}=0 \%\right]$, nasopharyngitis $[\mathrm{OR}=1.09,95 \% \mathrm{CI}$, $\left.0.41-2.89 ; P(Z)=0.87, P(Q)=0.88, I^{2}=0 \%\right]$, potential injection-site reactions $[\mathrm{OR}=0.80,95 \% \mathrm{CI}, 0.47-1.36 ; P(Z)=0.41$, $\left.P(Q)=0.23, I^{2}=32 \%\right]$ and any adverse events $[\mathrm{OR}=0.87$, 95\% CI, 0.74-1.04; $P(Z)=0.13, P(Q)=0.75, I^{2}=0 \%$ ] (Fig. 4). The subgroup analysis showed the same results, in the placebo and ezetimibe groups. The outcomes are presented in Table V.

Publication bias and sensitivity analysis. The funnel plots of these direct comparison studies indicated no evidence of publication bias, therefore are not included in the present study. Furthermore, the sensitivity analysis in the direct comparison was conducted by removing the largest study when a significant result was observed, the results remained unchanged (data not shown).

\section{Discussion}

The results of the current meta-analysis indicated that evolocumab was associated with a reduced risk of muscle-associated events when compared with ezetimibe, and different doses of evolocumab resulted in the same outcomes with regard to efficacy and safety. In the direct meta-analysis, the two doses of evolocumab appeared to exert a significant LDL-C lowering effect. As a fully human monoclonal antibody, evolocumab offers promising therapeutic applications in the control of PCSK9-regulated pathologies; inhibiting direct binding of PCSK9 and LDL receptors, reducing the degradation of the receptor, increasing LDL receptor activity on the hepatocyte surface and, ultimately, improving the uptake of plasma lipoprotein $(24,25)$. Within the above-mentioned mechanism, 


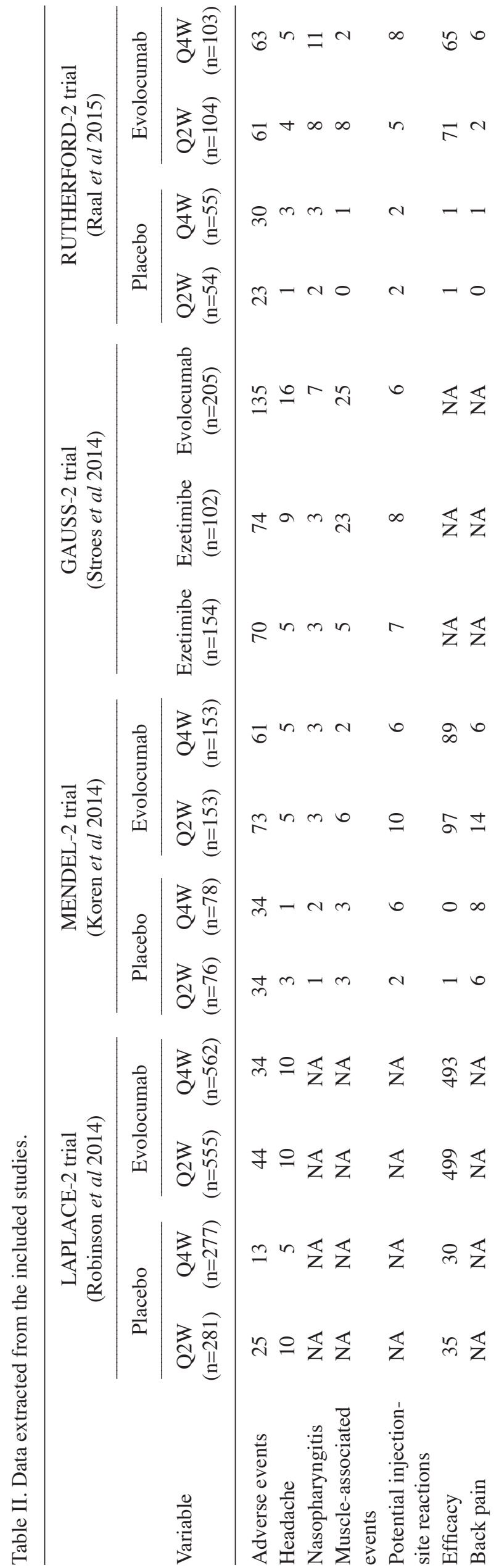

evolocumab has demonstrated significant reduction in LDL-C levels (6-10). Furthermore, in the current safety analysis, a significant difference was observed in the muscle-associated events group when the evolocumab group was compared with the ezetimibe group, which suggested that evolocumab was associated with fewer muscle-associated events than ezetimibe. Therefore, evolocumab was demonstrated to be safe and well tolerated.

In previous phase 1 and phase 2 trials $(14,26)$, no significant differences were identified in efficacy between the intravenous and subcutaneous groups, and evolocumab was characterized by a dose-dependent LDL-C reduction in terms of effect and duration. The higher the dosage that patients take, the longer the duration of the effect. Therefore, two doses are commonly administered; $140 \mathrm{mg}$ evolocumab, subcutaneously, every 2 weeks and $420 \mathrm{mg}$ evolocumab, subcutaneously, every 4 weeks. The head-to-head comparison of evolocumab $140 \mathrm{mg}$ Q2W vs. evolocumab $420 \mathrm{mg}$ Q4W indicated no significant differences in efficacy and any adverse events, including back pain, headache, nasopharyngitis, muscle-associated events and potential injection-site reactions. This high-dosage, long-interval administration of evolocumab $420 \mathrm{mg}$ Q4W is desirable. The results imply that clinicians should preferentially administer evolocumab $420 \mathrm{mg}$ Q4W in order to improve patient compliance and convenience. As there was no direct evidence of a comparison between evolocumab $140 \mathrm{mg}$ Q2W and evolocumab $420 \mathrm{mg}$ Q4W, an adjusted indirect comparison was made in the present study to evaluate the efficacy and safety of different doses of evolocumab. Random errors are sources of discrepancies between the direct and the adjusted indirect comparison. As the adjusted indirect comparison widens the confidence interval, infrequent significant differences may be caused. Therefore, there remains a lack of direct evidence as to whether evolocumab $140 \mathrm{mg}$ Q2W and evolocumab $420 \mathrm{mg}$ Q4W possess different efficacy and safety.

However, there are various key issues that require attention with regard to investigating PCSK9 inhibitors. It remains to be elucidated as to whether a reduction in LDL-C levels using a PCSK9 inhibitor may result in a reduction in cardiovascular events. Therefore, long-term, extensive, randomized clinical trials with definite cardiovascular endpoints are required. In addition, a long-term follow-up of security and tolerance is required to establish whether PCSK 9 inhibitors elicit an immune response, which may lead to a loss of responsiveness to treatment. Furthermore, although injectable treatment reduces the dosing frequency, patient acceptance levels should be considered and relevant guidance is required. Finally, monoclonal antibodies are expensive, which presents a limitation for their clinical application.

In conclusion, according to the current meta-analysis outcomes, evolocumab presents as an efficacious, safe and promising therapeutic strategy for hypercholesterolemia and the associated cardiovascular diseases. The head-to-head comparison of evolocumab $140 \mathrm{mg}$ Q2W vs. evolocumab $420 \mathrm{mg}$ Q4W indicated no significant differences in efficacy and adverse events. Furthermore, in the safety analysis, evolocumab had a reduced risk of muscle-associated events when compared with ezetimibe and the placebo groups. 
Table III. All pooled ORs comparing evolocumab $140 \mathrm{mg}$ Q2W or evolocumab $420 \mathrm{mg}$ Q4W vs. placebo [the fixed-model was used for smaller heterogeneity $\left(I^{2}<50 \%, \chi^{2}\right.$ test; two-tailed $\left.\mathrm{P}<0.1\right)$, otherwise the random model was used].

\begin{tabular}{lrccccccc}
\hline Variable & OR & $95 \%$ CI & $\chi^{2}$ & Freedom & OR & 95\% CI & $\chi^{2}$ & Freedom \\
\hline Efficacy & 72.35 & $(46.09-113.97)$ & 0.92 & 2 & 69.39 & $(43.65-110.31)$ & 1.23 & 2 \\
Adverse events & 1.13 & $(0.81-1.56)$ & 2.29 & 2 & 1.05 & $(0.74-1.50)$ & 0.98 & 2 \\
Back pain & 1.29 & $(0.51-3.23)$ & 0.21 & 1 & 0.87 & $(0.11-7.15)$ & 3.21 & 1 \\
Headache & 0.76 & $(0.33-1.36)$ & 1.45 & 2 & 1.11 & $(0.50-2.46)$ & 0.80 & 2 \\
Nasopharyngitis & 1.85 & $(0.51-6.80)$ & 0.05 & 1 & 1.44 & $(0.50-4.10)$ & 0.66 & 1 \\
Muscle-associated events & 2.17 & $(0.24-19.59)$ & 2.07 & 1 & 0.50 & $(0.12-2.02)$ & 0.51 & 1 \\
Potential injection-site reactions & 1.90 & $(0.62-5.85)$ & 0.41 & 1 & 0.91 & $(0.22-3.73)$ & 2.10 & 1 \\
\hline
\end{tabular}

OR, odds ratio; CI, confidence interval.

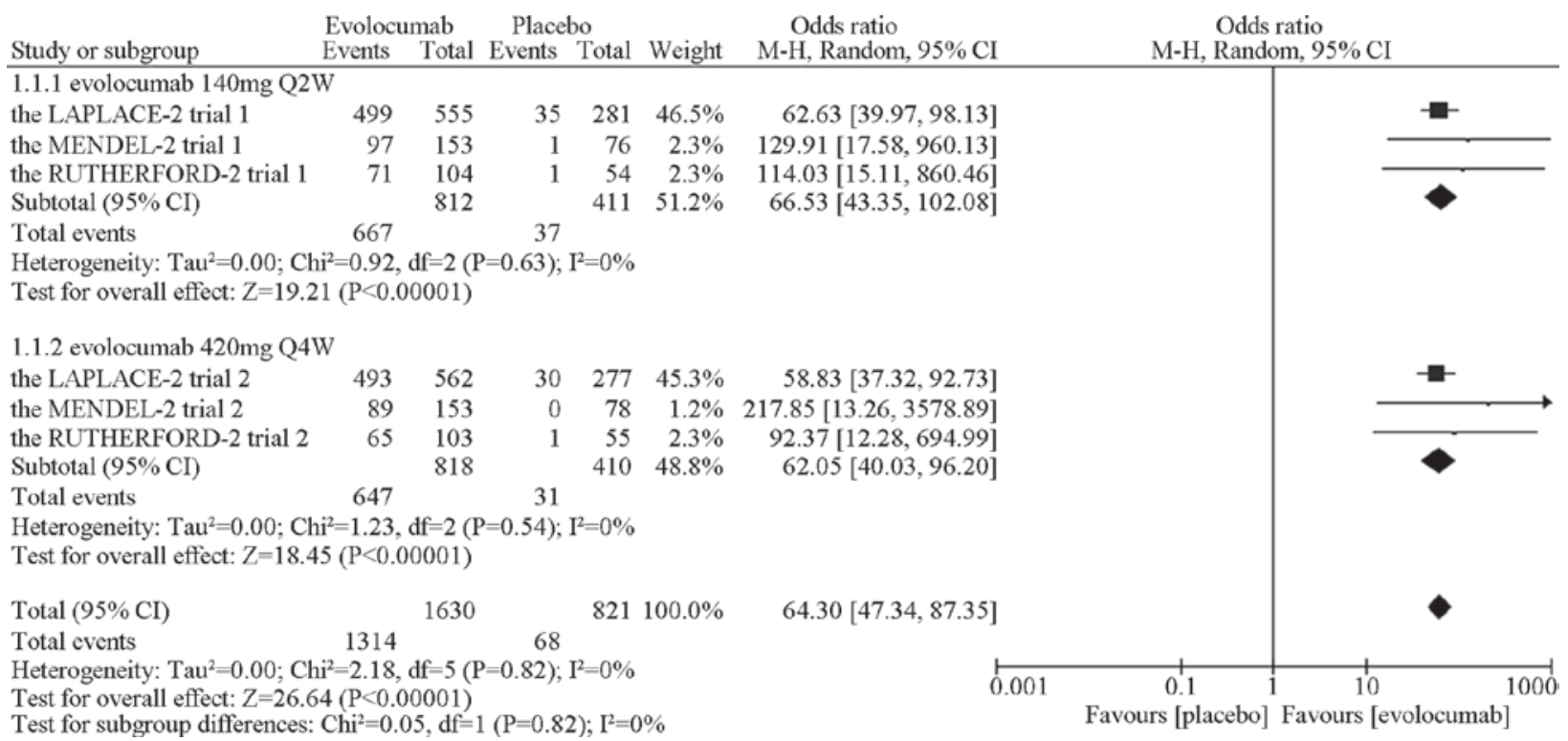

Figure 2. Efficacy of two different doses of evolocumab in reducing the level of low-density lipoprotein cholesterol to <70 mg/dl (1.8 mmol/1) when compared with a placebo. CI, confidence interval.

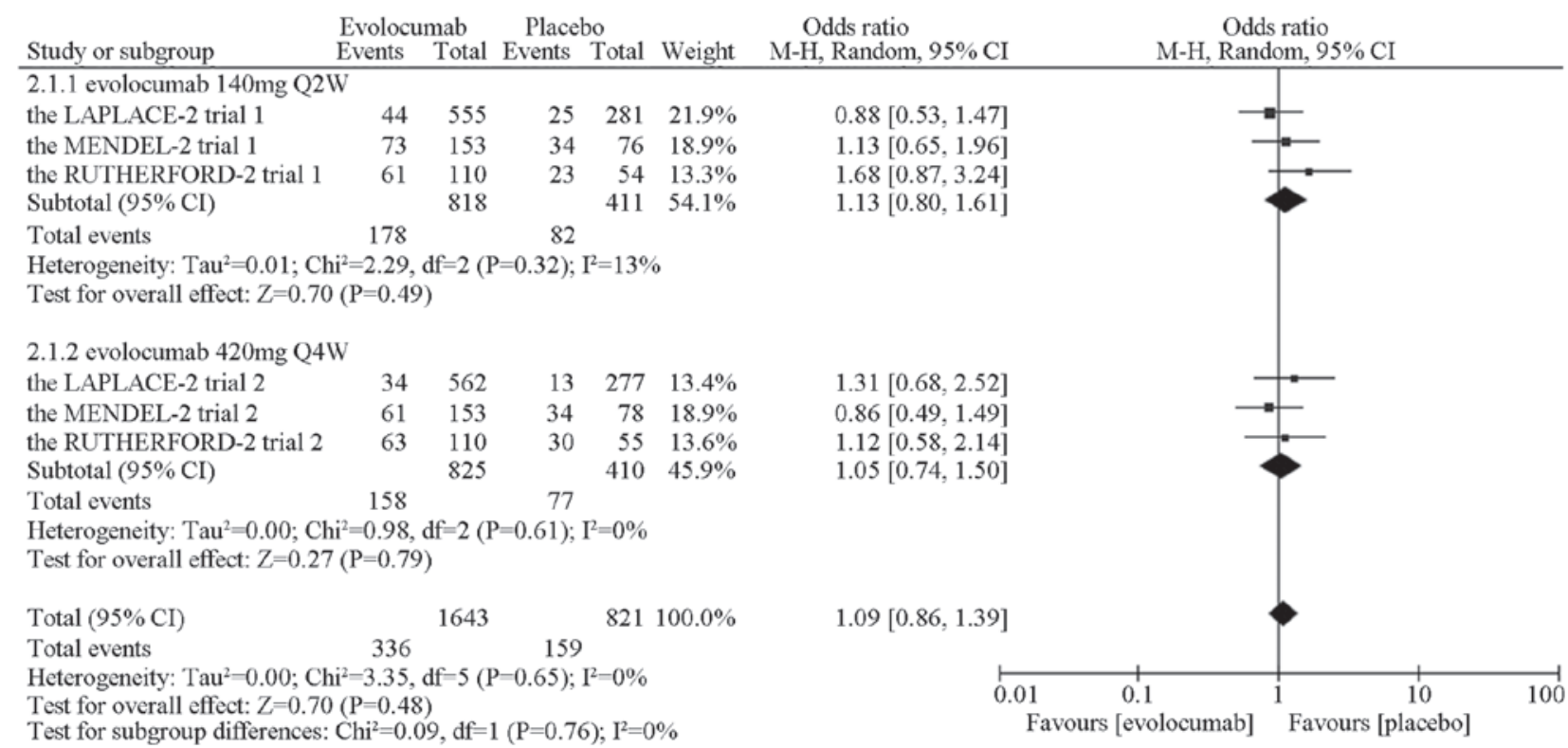

Figure 3. Safety of two different doses of evolocumab in any adverse events compared with a placebo. CI, confidence interval. 
Table IV. Adjusted indirect comparison of evolocumab 140 mg Q2W vs. evolocumab 420 mg Q4W.

\begin{tabular}{lcccc}
\hline Variable & Odds ratio & 95\% confidence interval & Z score & Two-tailed P-value \\
\hline Efficacy & 1.04 & $(0.55-1.99)$ & 0.13 & 0.90 \\
Adverse events & 1.08 & $(0.66-1.74)$ & 0.30 & 0.76 \\
Back pain & 1.48 & $(0.15-14.53)$ & 0.34 & 0.73 \\
Headache & 0.68 & $(0.23-2.06)$ & 0.67 & 0.50 \\
Nasopharyngitis & 1.28 & $(0.24-6.82)$ & 0.29 & 0.77 \\
Muscle-associated events & 4.43 & $(0.32-59.31)$ & 1.10 & 0.27 \\
Potential injection-site reactions & 2.09 & $(0.34-12.71)$ & 0.80 & 0.42
\end{tabular}

Table V. Evolocumab safety outcomes.

\begin{tabular}{|c|c|c|c|c|c|c|c|c|c|c|c|c|}
\hline & \multicolumn{4}{|c|}{ Evolocumab vs. placebo } & \multicolumn{4}{|c|}{ Evolocumab vs. ezetimibe } & \multicolumn{4}{|c|}{ Evolocumab vs. control } \\
\hline & OR & $95 \% \mathrm{CI}$ & $P(Q)$ & $P(Z)$ & OR & $95 \% \mathrm{CI}$ & $P(Q)$ & $P(Z)$ & OR & $95 \% \mathrm{CI}$ & $P(Q)$ & $P(Z)$ \\
\hline Adverse events & 0.88 & $(0.72-1.09)$ & - & 0.25 & 0.85 & $(0.63-1.17)$ & 0.46 & 0.32 & 0.87 & $(0.74-1.04)$ & 0.75 & 0.13 \\
\hline Headache & 0.63 & $(0.32-1.24)$ & - & 0.18 & 0.92 & $(0.47-1.81)$ & 0.84 & 0.82 & 0.77 & $(0.48-1.24)$ & 0.72 & 0.27 \\
\hline Nasopharyngitis & - & - & - & - & 1.09 & $(0.41-2.89)$ & 0.88 & 0.87 & 1.09 & $(0.41-2.89)$ & 0.88 & 0.87 \\
\hline $\begin{array}{l}\text { Muscle-associated } \\
\text { events }\end{array}$ & - & - & - & - & 0.54 & $(0.31-0.93)$ & 0.43 & 0.03 & 0.54 & $(0.31-0.93)$ & 0.43 & 0.03 \\
\hline $\begin{array}{l}\text { Potential injection-site } \\
\text { reactions }\end{array}$ & 0.94 & $(0.39-2.22)$ & - & 0.88 & 0.67 & $(0.21-2.12)$ & 0.10 & 0.49 & 0.80 & $(0.47-1.36)$ & 0.23 & 0.41 \\
\hline
\end{tabular}

OR, odds ratio; CI, confidence interval.

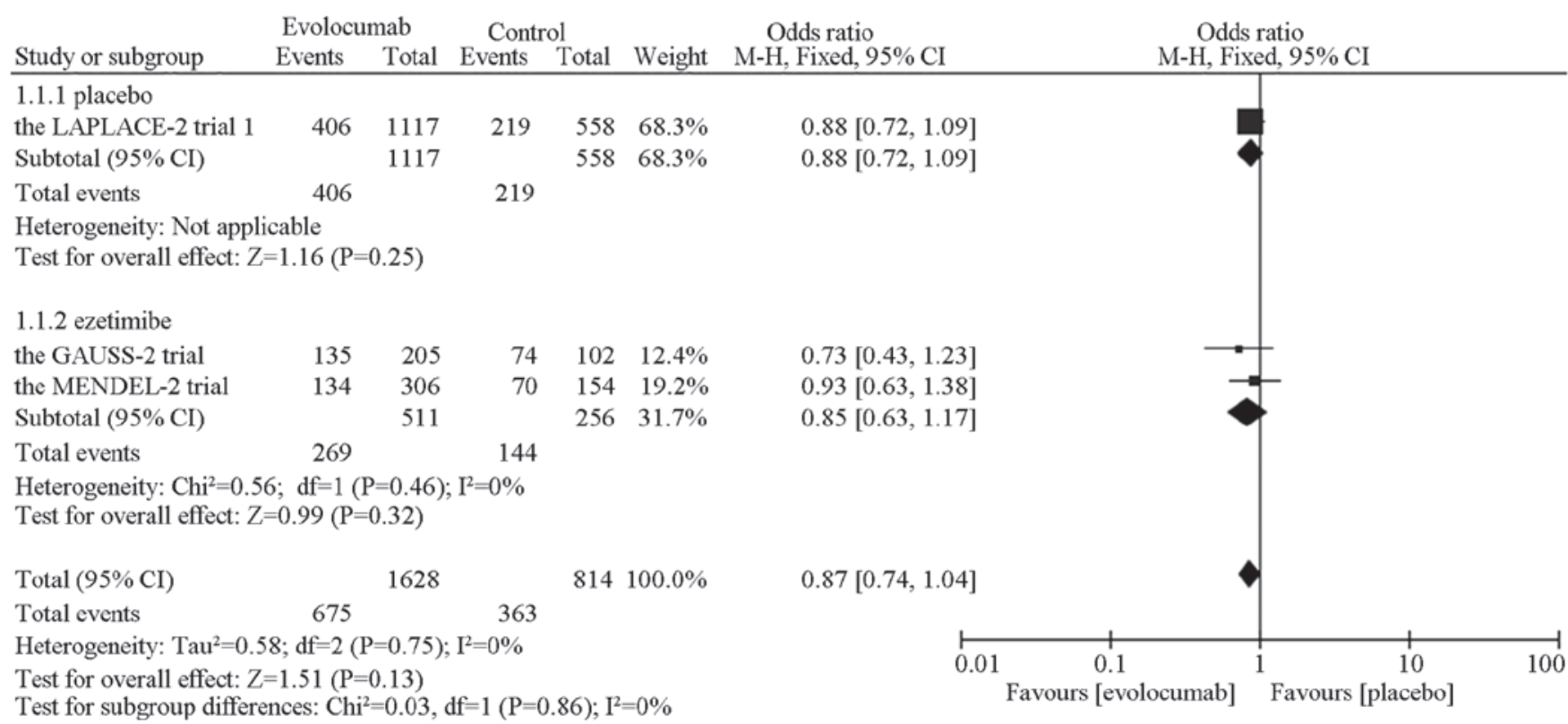

Figure 4. Forest plots of odds ratio with $95 \%$ CI for the safety of evolocumab in any adverse events compared with a placebo and ezetimibe. CI, confidence interval.

\section{Acknowledgements}

The present study was supported by grants from the National
Natural Science Foundation of China (grant no. 81170174), the Natural Scientific Fund of Jiangsu province (grant no. BK2011304). 


\section{References}

1. Stone NJ, Robinson JG, Lichtenstein AH, Bairey Merz CN, Blum CB, Eckel RH, Goldberg AC, Gordon D, Levy D, Lloyd-Jones DM, et al; American College of Cardiology/American Heart Association Task Force on Practice Guidelines: 2013 ACC/AHA guideline on the treatment of blood cholesterol to reduce atherosclerotic cardiovascular risk in adults: A report of the American College of Cardiology/American Heart Association Task Force on Practice Guidelines. Circulation 129 (Suppl 2): S1-S45, 2014

2. Jacobson TA, Ito MK, Maki KC, Orringer CE, Bays HE, Jones PH, McKenney JM, Grundy SM, Gill EA, Wild RA, et al: National Lipid Association recommendations for patient-centered management of dyslipidemia: Part 1 - executive summary. J Clin Lipidol 8: 473-488, 2014.

3. Anderson TJ, Grégoire J, Hegele RA, Couture P, Mancini GB, McPherson R, Francis GA, Poirier P, Lau DC, Grover S, et al: 2012 update of the Canadian Cardiovascular Society guidelines for the diagnosis and treatment of dyslipidemia for the prevention of cardiovascular disease in the adult. Can J Cardiol 29: 151-167, 2013.

4. Grundy SM; Expert Dyslipidemia Panel: An International Atherosclerosis Society Position Paper: Global recommendations for the management of dyslipidemia. J Clin Lipidol 7: 561-565, 2013.

5. Noto $\mathrm{D}$, Cefalù $\mathrm{AB}$ and Averna MR: Beyond statins: New lipid lowering strategies to reduce cardiovascular risk. Curr Atheroscler Rep 16: 414, 2014

6. Blom DJ, Hala T, Bolognese M, Lillestol MJ, Toth PD, Burgess L, Ceska R, Roth E, Koren MJ, Ballantyne CM, et al; DESCARTES Investigators: A 52-week placebo-controlled trial of evolocumab in hyperlipidemia. N Engl J Med 370: 1809-1819, 2014.

7. Robinson JG, Nedergaard BS, Rogers WJ, Fialkow J, Neutel JM, Ramstad D, Somaratne R, Legg JC, Nelson P, Scott R, et al; LAPLACE-2 Investigators: Effect of evolocumab or ezetimibe added to moderate- or high-intensity statin therapy on LDL-C lowering in patients with hypercholesterolemia: The LAPLACE-2 randomized clinical trial. JAMA 311: 1870-1882, 2014.

8. Koren MJ, Lundqvist P, Bolognese M, Neutel JM, Monsalvo ML, Yang J, Kim JB, Scott R, Wasserman SM and Bays H; MENDEL-2 Investigators: Anti-PCSK9 monotherapy for hypercholesterolemia: The MENDEL-2 randomized, controlled phase III clinical trial of evolocumab. J Am Coll Cardiol 63: 2531-2540, 2014.

9. Stroes E, Colquhoun D, Sullivan D, Civeira F, Rosenson RS, Watts GF, Bruckert E, Cho L, Dent R, Knusel B, et al; GAUSS-2 Investigators: Anti-PCSK9 antibody effectively lowers cholestero in patients with statin intolerance: The GAUSS-2 randomized, placebo-controlled phase 3 clinical trial of evolocumab. J Am Coll Cardiol 63: 2541-2548, 2014.

10. Raal FJ, Stein EA, Dufour R, Turner T, Civeira F, Burgess L, Langslet G, Scott R, Olsson AG, Sullivan D, et al, RUTHERFORD-2 Investigators: PCSK9 inhibition with evolocumab (AMG 145) in heterozygous familial hypercholesterolaemia (RUTHERFORD-2): A randomised, double-blind, placebo-controlled trial. Lancet 385: 331-340, 2015.

11. Stroup DF, Berlin JA, Morton SC, Olkin I, Williamson GD, Rennie D, Moher D, Becker BJ, Sipe TA and Thacker SB: Meta-analysis of observational studies in epidemiology: A proposal for reporting. Meta-analysis Of Observational Studies in Epidemiology (MOOSE) group. JAMA 283: 2008-2012, 2000.

12. Higgins JP, Thompson SG, Deeks JJ and Altman DG: Measuring inconsistency in meta-analyses. BMJ 327: 557-560, 2003.

13. Song F, Altman DG, Glenny AM and Deeks JJ: Validity of indirect comparison for estimating efficacy of competing interventions: Empirical evidence from published meta-analyses. BMJ 326: 472, 2003.

14. Giugliano RP, Desai NR, Kohli P, Rogers WJ, Somaratne R, Huang F, Liu T, Mohanavelu S, Hoffman EB, McDonald ST, et al: Efficacy, safety, and tolerability of a monoclonal antibody to proprotein convertase subtilisin/kexin type 9 in combination with a statin in patients with hypercholesterolaemia (LAPLACE-TIMI 57): A randomised, placebo-controlled, dose-ranging, phase 2 study. Lancet 380: 2007-2017, 2012.
15. Roth EM, Taskinen MR, Ginsberg HN, Kastelein JJ, Colhoun HM, Robinson JG, Merlet L, Pordy R and Baccara-Dinet MT: Monotherapy with the PCSK9 inhibitor alirocumab versus ezetimibe in patients with hypercholesterolemia: Results of a 24 week, double-blind, randomized Phase 3 trial. Int J Cardiol 176: 55-61, 2014

16. Robinson JG, Farnier M, Krempf M, Bergeron J, Luc G, Averna M, Stroes ES, Langslet G, Raal FJ, El Shahawy M, et al: ODYSSEY LONG TERM Investigators: Efficacy and safety of alirocumab in reducing lipids and cardiovascular events. N Engl J Med 372: 1489-1499, 2015.

17. Moriarty PM, Jacobson TA, Bruckert E, Thompson PD, Guyton JR, Baccara-Dinet MT and Gipe D: Efficacy and safety of alirocumab, a monoclonal antibody to PCSK9, in statin-intolerant patients: Design and rationale of ODYSSEY ALTERNATIVE, a randomized phase 3 trial. J Clin Lipidol 8: 554-561, 2014.

18. Raal FJ, Giugliano RP, Sabatine MS, Koren MJ, Langslet G, Bays H, Blom D, Eriksson M, Dent R, Wasserman SM, et al: Reduction in lipoprotein(a) with PCSK9 monoclonal antibody evolocumab (AMG 145): A pooled analysis of more than 1,300 patients in 4 phase II trials. J Am Coll Cardiol 63: $1278-1288,2014$

19. Sabatine MS, Giugliano RP, Wiviott SD, Raal FJ, Blom DJ, Robinson J, Ballantyne CM, Somaratne R, Legg J, Wasserman SM, et al; Open-Label Study of Long-Term Evaluation against LDL Cholesterol (OSLER) Investigators: Efficacy and safety of evolocumab in reducing lipids and cardiovascular events. N Engl J Med 372: 1500-1509, 2015.

20. Raal F, Scott R, Somaratne R, Bridges I, Li G, Wasserman SM and Stein EA: Low-density lipoprotein cholesterol-lowering effects of AMG 145, a monoclonal antibody to proprotein convertase subtilisin/kexin type 9 serine protease in patients with heterozygous familial hypercholesterolemia: The Reduction of LDL-C with PCSK9 Inhibition in Heterozygous Familial Hypercholesterolemia Disorder (RUTHERFORD) randomized trial. Circulation 126: 2408-2417, 2012.

21. Koren MJ, Scott R, Kim JB, Knusel B, Liu T, Lei L, Bolognese M and Wasserman SM: Efficacy, safety, and tolerability of a monoclonal antibody to proprotein convertase subtilisin/kexin type 9 as monotherapy in patients with hypercholesterolaemia (MENDEL): A randomised, double-blind, placebo-controlled, phase 2 study. Lancet 380: 1995-2006, 2012.

22. Sullivan D, Olsson AG, Scott R, Kim JB, Xue A, Gebski V, Wasserman SM and Stein EA: Effect of a monoclonal antibody to PCSK9 on low-density lipoprotein cholesterol levels in statin-intolerant patients: The GAUSS randomized trial. JAMA 308: 2497-2506, 2012.

23. Hirayama A, Honarpour N, Yoshida M, Yamashita S, Huang F, Wasserman SM and Teramoto T: Effects of evolocumab (AMG 145), a monoclonal antibody to PCSK9, in hypercholesterolemic, statin-treated Japanese patients at high cardiovascular risk - primary results from the phase 2 YUKAWA study. Circ J 78: 1073-1082, 2014

24. Urban D, Pöss J, Böhm M and Laufs U: Targeting the proprotein convertase subtilisin/kexin type 9 for the treatment of dyslipidemia and atherosclerosis. J Am Coll Cardiol 62: 1401-1408, 2013.

25. Banach M, Rizzo M, Obradovic M, Montalto G, Rysz J, Mikhailidis DP and Isenovic ER: PCSK9 inhibition - a novel mechanism to treat lipid disorders? Curr Pharm Des 19: 3869-3877, 2013.

26. Dias CS, Shaywitz AJ, Wasserman SM, Smith BP, Gao B, Stolman DS, Crispino CP, Smirnakis KV, Emery MG, Colbert A, et al: Effects of AMG 145 on low-density lipoprotein cholesterol levels: Results from 2 randomized, double-blind, placebo-controlled, ascending-dose phase 1 studies in healthy volunteers and hypercholesterolemic subjects on statins. J Am Coll Cardiol 60: 1888-1898, 2012. 